\title{
Germinação, formação de porta-enxertos e enxertia de cajueiro anão precoce, sob estresse salino ${ }^{1}$
}

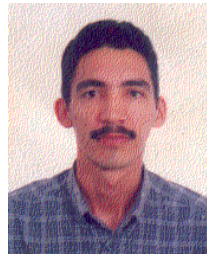

Idelfonso L. Bezerra ${ }^{2}$, Hans R. Gheyi ${ }^{3}$, Pedro D. Fernandes ${ }^{3}$, Francisco José de S. Santos ${ }^{4}$, Marcelo T. Gurgel ${ }^{2} \&$ Reginaldo G. Nobre ${ }^{2}$

\footnotetext{
1 Parte da Dissertação de Mestrado do primeiro autor apresentada à UFPB - Campina Grande, PB

${ }^{2}$ Mestrando, DEAg/CCT/UFCG. CEP 58109-970, Campina Grande, PB. E-mail: idelfonsolb@bol.com.br (Foto)

${ }^{3}$ DEAg/CCT/UFCG. Fone (83) 310-1285, Fax (83) 310-1307

${ }^{4}$ EMBRAPA/Agroindústria Tropical, Rua Dra. Sara Mesquita 2270, Pici, CP 3761, CEP 60511-110, Fortaleza, CE
}

Protocolo $20-22 / 2 / 2002$

\begin{abstract}
Resumo: Com o propósito de se avaliar os efeitos da salinidade da água de irrigação na germinação e no crescimento de dois porta-enxertos e no pegamento de enxertia de cajueiro Anão Precoce, conduziu-se um experimento no viveiro do Campo Experimental de Pacajus, pertencente à Embrapa Agroindústria Tropical, no Estado do Ceará. Os tratamentos, em blocos casualizados, consistiram de seis valores de condutividade elétrica da água (CEa: 0,$5 ; 1,5 ; 2,5 ; 3,5 ; 4,5$ e $5,5 \mathrm{dS} \mathrm{m}^{-1}$ ) e de dois clones (CCP06 e CCP1001), com quatro repetições, 54 plantas por parcela. As águas de irrigação foram preparadas mantendo-se a proporção de 7:2:1 entre os íons $\mathrm{Na}: \mathrm{Ca}: \mathrm{Mg}$, respectivamente. Foram avaliados, aos 25 e 40 dias após semeadura, os efeitos sobre as variáveis percentagem e número de dias para germinação, número de folhas, altura de plantas, diâmetro de caule e fitomassa total; o índice de pegamento do enxerto foi avaliado aos 30 dias após a enxertia. Com exceção de percentagem de germinação, as demais variáveis foram afetadas negativamente pela salinidade da água de irrigação; entre os clones, o crescimento de CCP1001 foi mais prejudicado.
\end{abstract}

Palavras-chave: Anacardium occidentale L., condutividade elétrica, crescimento

\section{Germination, formation of rootstocks and grafting of precocious dwarf cashew under salinity stress}

\begin{abstract}
With the purpose of evaluating effects of salinity of the irrigation water in different genotypes of precocious dwarf cashew, an experiment was conducted in greenhouse at the Experimental Station of Pacajus, belonging to Embrapa Tropical Agroindústria in the State of Ceará. The treatments in randomized block design consisted of six levels of electrical conductivity of water (ECw: $0.5 ; 1.5 ; 2.5 ; 3.5 ; 4.5$ and $5.5 \mathrm{dS} \mathrm{m}^{-1}$ ) and two types of seedlings (CCPO6 and CCP1001) with four replications, totaling 48 units each consisting of 54 plants. The irrigation waters were prepared maintaining a proportion of 7:2:1 for the ions $\mathrm{Na:Ca:Mg}$. The effects of the salinity were evaluated on germination, germination period, number of leaves, plant height, stem diameter and total dry weight 25 and 40 days after planting; the plantlings were evaluated 30 days after grafting. With the exception of germination percentage, other variables were found to be affected negatively by salinity of the irrigation water and between clones the growth of CCP1001 was affected more adversely.
\end{abstract}

Key words: Anacardium occidentale L., electrical conductivity, growth

\section{INTRODUÇÃO}

O cajueiro é uma cultura com grandes perspectivas econômicas no mercado internacional e participa de forma expressiva como atividade econômica e social para o Nordeste. No Brasil, os Estados do Ceará, Rio Grande do Norte e Piauí produzem aproximadamente 126 mil toneladas de castanhas de caju, em uma área de 630 mil hectares. Desse total, são exportadas 28 mil toneladas de castanha, garantindo renda para mais de $300 \mathrm{mil}$ pessoas e gerando divisas superiores a 135 milhões de dólares anuais (FNP, 1998).

Dentre os resultados de pesquisa com essa espécie, na região, destaca-se a criação de novas variedades mais produtivas, como o cajueiro Anão Precoce, com índices de produtividade bem superiores aos dos genótipos tradicionais. Esse novo material tem características de produção precoce, inicia o ciclo produtivo a partir do segundo ou terceiro ano após plantio e atinge estabilidade produtiva aos cinco anos, 
podendo ser cultivado tanto em áreas irrigadas quanto sob condições de sequeiro. Tem ocorrido, também, aperfeiçoamento das técnicas de propagação, envolvendo preparação de substratos e acondicionamento de mudas, permitindo a obtenção de plantas mais vigorosas, por melhorar a eficiência da nutrição e baixar os custos de produção, por economia de espaço, água e de substrato (Silva \& Silva, 1999).

A salinidade dos solos tem se constituído num dos mais sérios problemas para a agricultura irrigada em diversas partes do mundo (Coelho, 1983). Para Postel (1989), em nível global, um quarto de toda a área irrigada encontra-se seriamente afetado por sais, especialmente nos locais onde a irrigação é praticada sem manejo racional de água e de solo. No Nordeste do Brasil, são aproximadamente nove milhões de hectares, envolvendo sete Estados. Na Bahia encontra-se a maior área de solos afetados por sais, cerca de $44 \%$ da área salinizada, seguida pelo Ceará, com aproximadamente 25,5\% (Fageria \& Gheyi, 1997).

Existe grande variabilidade de comportamento entre as culturas com relação aos limites de tolerância à salinidade. Genótipos de uma mesma espécie podem responder de modo diferente aos efeitos salinos, nas várias fases de seu desenvolvimento (Maas \& Hoffmann, 1977; Maas, 1986). Todavia, a maioria das espécies cultivadas de importância econômica é relativamente sensível à salinidade na germinação e quase todas as culturas não toleram condições permanentes de salinidade no solo (Kramer, 1984). Em relação a cajueiro, os estudos existentes de salinidade abrangem apenas a fase de formação de porta-enxertos sem haver, entretanto, trabalhos em tubetes e abrangendo enxertia.

Este trabalho teve como objetivo avaliar os efeitos da salinidade da água de irrigação na germinação de sementes e crescimento de dois porta-enxertos e no índice de pegamento de enxertia do cajueiro Anão Precoce.

\section{MATERIAL E MÉTODOS}

O ensaio foi conduzido em um viveiro do Campo Experimental de Pacajus, Estado do Ceará, no período de janeiro a maio de 2001.

Os tratamentos consistiram de seis níveis de salinidade da água de irrigação expressos pela condutividade elétrica (CEa): $0,5,1,5,2,5,3,5,4,5$ e $5,5 \mathrm{dS} \mathrm{m}^{-1}$, denominados de $\mathrm{S}_{1}$ a $\mathrm{S}_{6}$, utilizados na irrigação de mudas de dois clones de cajueiro (Anacardium occidentale L.) Anão Precoce, denominados de $\mathrm{C}_{1}$ (CCP06) e $\mathrm{C}_{2}$ (CCP1001), em disposição fatorial 6x2. O delineamento experimental foi em blocos casualizados, com quatro repetições, constituindo-se a parcela de 54 plantas.

O substrato foi composto de uma mistura de casca de arroz carbonizada, palha de carnaúba triturada e material da camada superficial de um Neossolo, na proporção 2:1:1, sendo submetido a análises para fins de salinidade (Richards, 1954) e de fertilidade (EMBRAPA, 1997), cujos dados estão apresentados na Tabela 1. Em seguida, a mistura foi acondicionada em tubetes plásticos de $19 \mathrm{~cm}$ de altura e $6,3 \mathrm{~cm}$ de diâmetro, com capacidade de $288 \mathrm{~cm}^{3}$, abertos na parte inferior para facilitar a drenagem e conseqüente lixiviação dos sais.
Tabela 1. Características químicas do substrato utilizado no experimento

\begin{tabular}{|c|c|}
\hline Características Químicas & Valor \\
\hline \multicolumn{2}{|l|}{ Complexo sortivo, $\mathrm{mmol}_{\mathrm{c}} \mathrm{dm}^{-3}$} \\
\hline Cálcio & 19,08 \\
\hline Magnésio & 9,97 \\
\hline Sódio & 43,00 \\
\hline Potássio & 17,50 \\
\hline Hidrogênio + Alumínio (Acidez Potencial) & 26,00 \\
\hline Soma de bases (S) & 89,55 \\
\hline Capacidade de troca de cátions (CTC) & 115,55 \\
\hline Saturação de bases (V), \% & 77,50 \\
\hline Percentagem de sódio trocável (PST) & 37,21 \\
\hline Matéria orgânica, $\mathrm{g} \mathrm{dm}^{-3}$ & 117,99 \\
\hline Fósforo (resina), $\mathrm{mg} \mathrm{dm}^{-3}$ & 48,87 \\
\hline Manganês; $\mathrm{mg} \mathrm{dm}^{-3}$ & 11,54 \\
\hline Zinco; $\mathrm{mg} \mathrm{dm}^{-3}$ & 1,65 \\
\hline Cobre; $\mathrm{mg} \mathrm{dm}^{-3}$ & 0,21 \\
\hline Ferro; $\mathrm{mg} \mathrm{dm}^{-3}$ & 41,34 \\
\hline pH (água $1: 2,5)$ & 5,40 \\
\hline CE do extrato de saturação; dS m ${ }^{-1}$ & 1,60 \\
\hline
\end{tabular}

No preparo das águas de irrigação empregou-se a relação entre CEa e concentração de sais $\left(\mathrm{mmol}_{\mathrm{c}} \mathrm{L}^{-1}=\mathrm{CEa} \times 10\right)$, como sugerem Rhoades et al. (1992), válida para a amplitude entre 0,1 e 5,0 dS m $\mathrm{m}^{-1}$. As águas foram preparadas a partir de soluções $1 \mathrm{~N} \mathrm{de} \mathrm{NaCl}, \mathrm{CaCl}_{2} \cdot 2 \mathrm{H}_{2} \mathrm{O}$ e $\mathrm{MgCl}_{2} \cdot 6 \mathrm{H}_{2} \mathrm{O}$, utilizando-se da água de um poço artesiano existente no Campo Experimental para diluição.

A quantidade de cada componente utilizado no preparo das águas de irrigação foi determinada de forma a se obter a CEa do respectivo tratamento, mantendo-se a proporção 7:2:1 entre $\mathrm{Na}: \mathrm{Ca}: \mathrm{Mg}$, respectivamente, e considerando-se as quantidades desses íons presentes na água de poço; essa proporção, segundo Medeiros (1992), é representativa para a maioria das fontes de água do Nordeste.

Após o enchimento dos tubetes, o substrato foi submetido a 12 lavagens com aplicações de 2,0 L de água dos respectivos tratamentos, para lixiviação do excesso de sais. Realizou-se a semeadura em 16 de fevereiro de 2001, usando-se uma castanha por tubete, na profundidade de aproximadamente $3 \mathrm{~cm}$ (EMBRAPA, 1993). As irrigações aconteceram ao final de cada dia, através de regadores manuais, fornecendo-se $5 \mathrm{~L}$ de água do respectivo tratamento.

A enxertia foi realizada aos 40 dias após a semeadura, através do método de fenda lateral, sendo utilizado como enxerto o clone CCP76.

Aos 30 dias após a emergência das plântulas fez-se uma adubação com $12,5 \mathrm{~mL}$ por planta da solução recomendada por Murashige \& Skoog ${ }^{1}$ (1962). Os tratos fitossanitários foram feitos conforme a necessidade (Cabarjal et al. 1995).

Procedeu-se a avaliação diária da contagem do número de sementes germinadas, tendo-se como critério a emergência do epicótilo na superfície do tubete. A percentagem final foi determinada aos 25 dias após a semeadura (DAS), conforme

\footnotetext{
${ }^{1}$ Composição (mg L-1) - macronutrientes: $\mathrm{NH}_{4} \mathrm{NO}_{3}(1650) ; \mathrm{KNO}_{3}(1900) ; \mathrm{CaCl}_{2} \cdot 2 \mathrm{H}_{2} \mathrm{O}(440) ; \mathrm{MgSO}_{4} \cdot 7 \mathrm{H}_{2} \mathrm{O}$ (370) e $\mathrm{KH}_{2} \mathrm{PO}_{4}(170)$; micronutrientes: $\mathrm{H}_{3} \mathrm{BO}_{3}(6,2) ; \mathrm{MnSO}_{4} \cdot 4 \mathrm{H}_{2} \mathrm{O}(22,3) ; \mathrm{ZnSO}_{4} \cdot 7 \mathrm{H}_{2} \mathrm{O}(8,6) ; \mathrm{KI}(0,83)$; $\mathrm{CuSO}_{4} 5 \mathrm{H}_{2} \mathrm{O}(0,025) ; \mathrm{CoCl}_{2} .6 \mathrm{H}_{2} \mathrm{O}(0,025) ; \mathrm{Na}_{2} \mathrm{MoO}_{4} 2 \mathrm{H}_{2} \mathrm{O}(0,25) \mathrm{Na}_{2}$ EDTA $(37,3)$ e $\mathrm{FeSO}_{4} \cdot 7 \mathrm{H}_{2} \mathrm{O}$ $(27,8)]$
} 
limite recomendado por Cabarjal et al. (1995). O número de dias para a germinação das sementes (NDG) foi obtido a partir da expressão: $\mathrm{NDG}=\sum \mathrm{n}_{\mathrm{i}} \mathrm{i} / \sum \mathrm{n}_{\mathrm{i}}$, sendo $\mathrm{n}_{\mathrm{i}}=$ número de sementes germinadas no dia $\mathrm{i}(\mathrm{i}=1,2, \ldots \mathrm{n})$, adaptada de Vieira \& Carvalho (1994).

Houve amostragens de 16 plantas por tratamento ( 4 por repetição) aos 25 e aos 40 DAS para avaliação do número de folhas (NF), altura de plantas (AP), diâmetro do caule (DC) e fitomassa seca total (FST); aos 30 dias após a enxertia, obtiveram-se os dados de percentagem de pegamento de enxerto.

Todos os dados foram submetidos à análise de variância pelo teste "F" e de regressão polinomial, seguindo-se orientações contidas em Ferreira (2000).

\section{RESULTADOS E DISCUSSÃO}

\section{Germinação}

A salinidade da água de irrigação não afetou, significativamente, o percentual de germinação (PG), na contagem realizada 25 dias após a semeadura (DAS), mas influenciou na duração do período germinativo $(\mathrm{p}<0,01)$, avaliado através do número de dias para germinação (NDG), segundo os dados expostos na Tabela 2.

Tabela 2. Resumo de ANAVA para percentagem de germinação (PG) e número de dias para germinação (NDG) aos 25 dias após a semeadura (DAS)

\begin{tabular}{|c|c|c|}
\hline \multirow{2}{*}{ Causa da Variação } & \multicolumn{2}{|c|}{ Quadrado Médio } \\
\hline & PG & NDG \\
\hline Salinidade (S) & $3,0435 \mathrm{~ns}$ & $6,6155 * *$ \\
\hline Reg. Pol. Linear & - & $16,2771 * *$ \\
\hline Reg. Pol. Quadr. & - & $0,1473 \mathrm{~ns}$ \\
\hline Desv. Reg. & - & $0,0303 \mathrm{~ns}$ \\
\hline Clones (C) & $185,8894 * *$ & $1,7480 \mathrm{~ns}$ \\
\hline $\mathrm{S} \times \mathrm{C}$ & $3,3848 \mathrm{~ns}$ & $0,4479 \mathrm{~ns}$ \\
\hline Bloco & $1,2134 \mathrm{~ns}$ & $0,7035 \mathrm{~ns}$ \\
\hline Resíduo & 8,1310 & 0,4655 \\
\hline $\mathrm{CV}(\%)$ & 2,9576 & 3,8966 \\
\hline Porta-enxertos & \multicolumn{2}{|c|}{ Médias } \\
\hline $\mathrm{C}_{1}(\mathrm{CCP} 06)$ & $98,3804 \mathrm{a}$ & $17,3192 \mathrm{a}$ \\
\hline $\mathrm{C}_{2}(\mathrm{CCP} 1001)$ & 94,4446 b & $17,7008 \mathrm{a}$ \\
\hline dms (clones) & 1,6758 & 0,4010 \\
\hline
\end{tabular}

O efeito da salinidade sobre NDG foi linear e crescente (Fig. 1), com taxa de incremento relativo de $2,95 \%$, por aumento unitário de CEa em relação a $\mathrm{S}_{1}\left(0,5 \mathrm{dS} \mathrm{m}^{-1}\right)$.

Variou entre os clones o percentual de germinação de sementes, sem, contudo, depender da ação da salinidade, pela não significância da interação S x C (Tabela 2). As sementes do clone $\mathrm{C}_{1}$ (CCP06) germinaram em maior percentual $(98,38 \%)$ do que as do clone $\mathrm{C}_{2}$ (CCP1001), que atingiram 94,44\%, diferindo estatisticamente entre si $(\mathrm{p}<0,05)$.

$\mathrm{O}$ efeito significativo da salinidade da água, aumentando o número de dias para germinação, pode estar relacionado à redução do potencial osmótico da solução do solo $\left(\psi_{\mathrm{o}}\right)$, causada pelo incremento de sais solúveis no substrato, resultando em diminuição da disponibilidade hídrica do solo e dificultando o

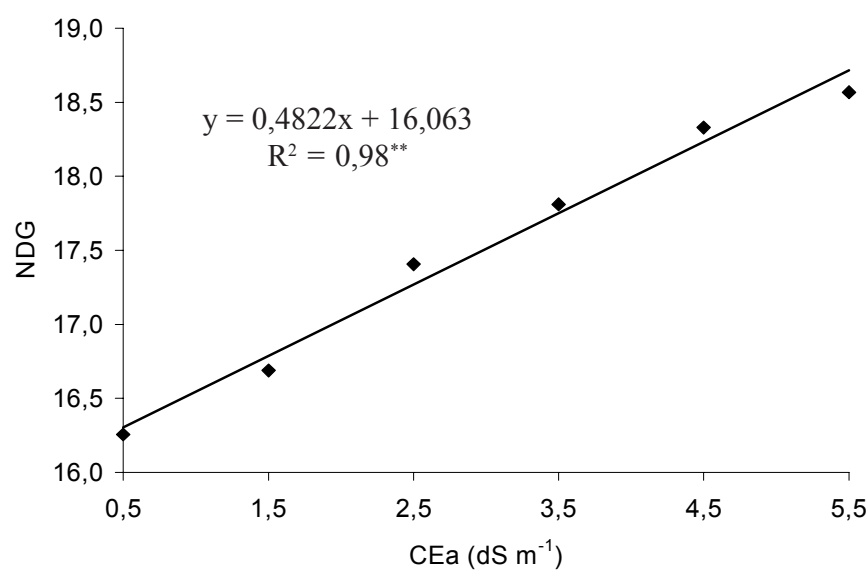

Figura 1. Número médio de dias para germinação (NDG) de clones de cajueiro Anão Precoce, em função da condutividade elétrica da água de irrigação $(\mathrm{CEa})$

processo de absorção de água pelas sementes (Menguel \& Kirkby, 1987; Rhoades \& Loveday, 1990).

\section{Formação de porta-enxertos}

O número de folhas, aos 25 e 40 DAS, diminuiu linearmente com o aumento da salinidade da água de irrigação (Fig. 2A), com decréscimo relativo por incremento unitário de $\mathrm{CEa}$ (comparado a $\mathrm{S}_{1}$ ) de 5,91 e 2,41\% aos 25 e 40 DAS, respectivamente. Em nenhuma das épocas analisadas foi constatada diferença significativa no número de folhas entre clones e, pelo fato de não ser significativa a interação $\mathrm{S}$ x C, foi similar o efeito da salinidade nos porta-enxertos.

Meireles (1999) observou, também, efeito semelhante da salinidade da água de irrigação sobre germinação dos clones CCP06 e CCP1001 de cajueiro, aos 30 e 60 DAS; aquele autor registrou diminuição significativa no número de folhas das plantas quando irrigadas com água de CE superior a $2,04 \mathrm{dS} \mathrm{m}^{-1}$.

O crescimento das plantas em altura (Fig. 2B) foi inibido de forma significativa pela salinidade da água de irrigação, em ambos os períodos de avaliação. Aos 25 DAS o efeito foi semelhante nos dois genótipos de cajueiros, obtendo-se a equação linear $y=-2,0634 x+19,757\left(R^{2}=0,98\right)$, relacionando a altura de plântulas (y) e o nível de CEa (x), com decréscimo unitário de 11,02\%, em comparação com $\mathrm{S}_{1}$. Entretanto, aos 40 DAS o efeito da irrigação com água salina variou entre clones, representado graficamente na Figura 2B; a altura das plantas do clone CCP 1001 foi mais prejudicada pela salinidade, com redução de $8,59 \%$ por incremento unitário de $\mathrm{CEa}$, sendo de 7,71 em CCP06. Meireles (1999), estudando o crescimento desses dois porta-enxertos, encontrou, da mesma forma, efeito significativo da interação (salinidade $\mathrm{x}$ clone) sobre a altura de planta, aos 60 dias após semeadura, sendo o clone CCP1001 mais afetado que o CCP06, quando irrigados com água de $\mathrm{CEa}$ a partir de $2,04 \mathrm{dS} \mathrm{m}^{-1}$.

O diâmetro do caule (DC) de ambos os clones sofreu interferência significativa da salinidade da água de irrigação, aos 25 e 40 DAS (Fig. 2C). Na primeira data o efeito variou entre os clones, sendo, entretanto, de magnitude estatisticamente semelhante na segunda avaliação (40 DAS). Aos 25 DAS, os valores de diâmetro do caule das plântulas CCP06 decresceram 
A.
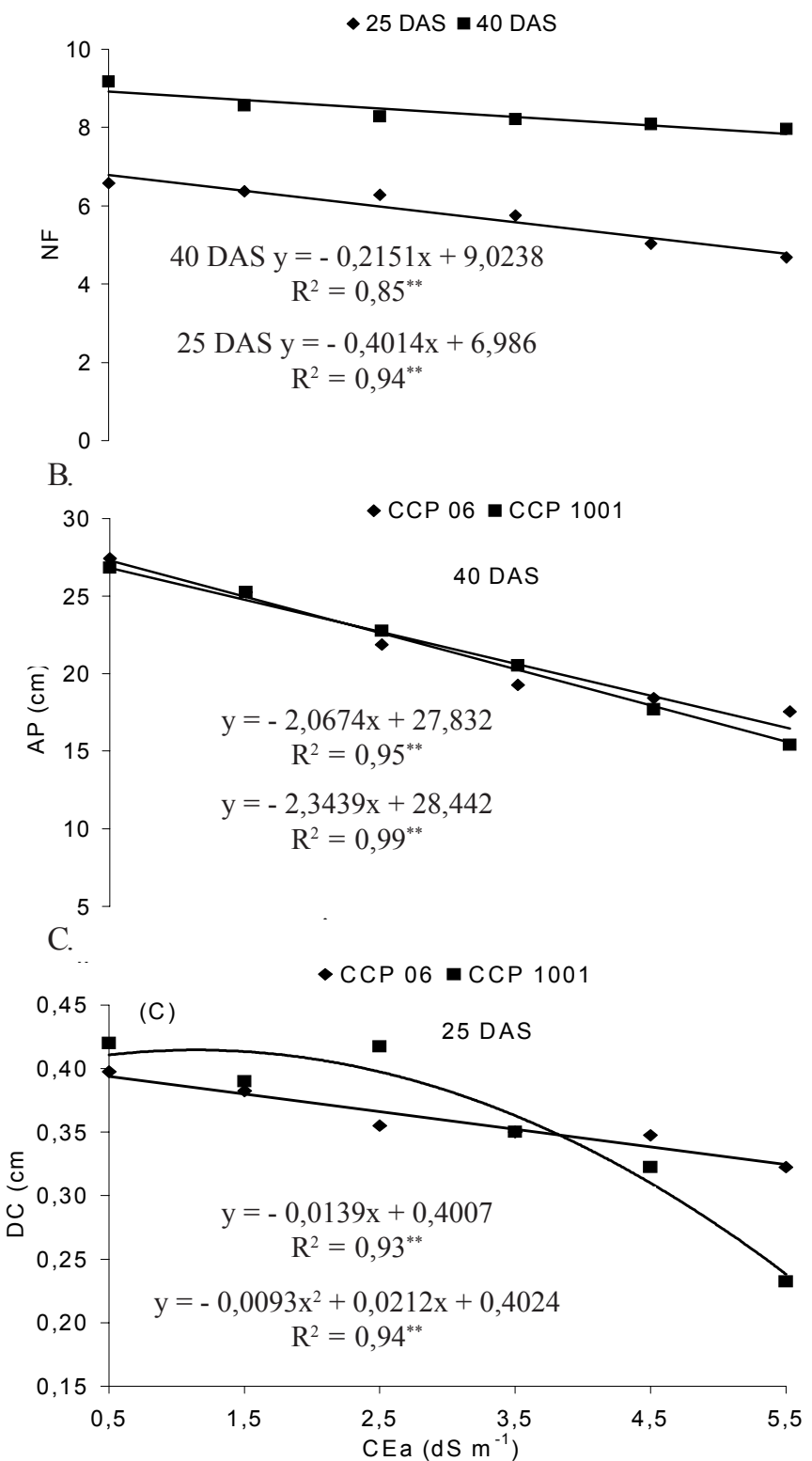

Figura 2. Número de folhas (NF) aos 25 e 40 DAS (A), altura de planta (AP) e diâmetro de caule (DC) dos clones CCP06 e CCP1001 (B e C) em função da salinidade da água de irrigação

linearmente e os de CCP1001 diminuíram de forma quadrática (Fig. 2C). No clone CCP06 o decréscimo em DC por incremento unitário de $\mathrm{CEa}$, comparado a $\mathrm{S}_{1}$, foi de $3,53 \%$, enquanto em CCP1001 o diâmetro do caule diminuiu $0,63,3,26,11,68,24,64$ e $42,12 \%$, quando as plântulas foram irrigadas com águas de condutividade elétrica de $1,5,2,5,3,5,4,5$ e $5,5 \mathrm{dS} \mathrm{m}^{-1}$, respectivamente. Observa-se, ainda, na Figura $2 \mathrm{C}$ que em condições de salinidade de até $3,8 \mathrm{dS} \mathrm{m}^{-1}$ o DC do clone CCP1001 foi maior que o de CCP06, invertendo o comportamento nos valores superiores a esse nível de salinidade. Portanto, nos níveis mais altos de CEa o genótipo CCP06 foi mais tolerante à salinidade, até aos 25 DAS.

Quinze dias após essa primeira avaliação (40 DAS), ambos os clones foram afetados de modo igual pela salinidade, sendo linear o efeito $\left(\mathrm{y}=-0,0127 \mathrm{x}+0,4227, \mathrm{R}^{2}=0,89\right)$, com decréscimo de $3,05 \%$ por incremento unitário de CEa. Comportamento semelhante foi obtido por Soares (1998), trabalhando com clones de cajueiro Anão Precoce, aos 45 e 65 dias após a germinação, em função de diferentes níveis de salinidade do substrato, afetando igualmente o diâmetro do caule de todos os genótipos.

\section{Fitomassa seca total}

A fitomassa seca total (FST) foi afetada pela salinidade da água de irrigação $(p<0,01)$, com efeito linear depressivo nas duas épocas de avaliação, aos 25 e 40 dias após a semeadura. Conforme o modelo matemático obtido (Fig. 3), foram de 5,91 e $6,96 \%$ os decréscimos por incremento unitário de CEa (comparados a $\mathrm{S}_{1}$ ), respectivamente aos 25 e 40 DAS.

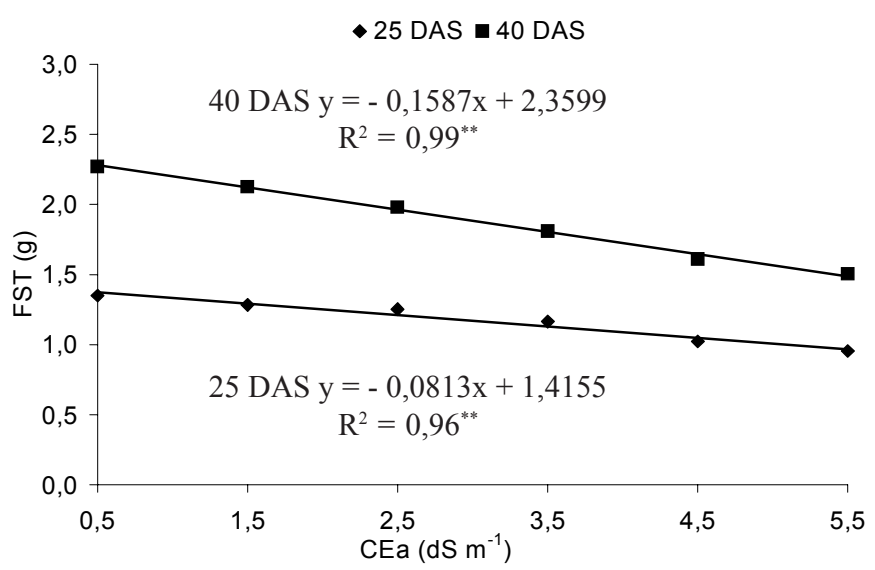

Figura 3. Fitomassa seca total (FST) em função da condutividade elétrica da água de irrigação $(\mathrm{CEa})$ aos 25 e 40 dias após semeadura (DAS) de dois porta-enxertos de cajueiro anão precoce

A salinidade inibiu menos o crescimento das raízes que o da parte aérea. Segundo Fageria (1989), essa é uma forma de adaptação da planta, aumentando a sua capacidade de absorção de água em detrimento da taxa de transpiração. Por isso, a fitomassa seca da planta constitui uma importante variável para análise de crescimento, em resposta aos efeitos da salinidade. Reduções na produção de fitomassa seca de plantas cultivadas em condições de estresse salino foram, também, observadas por Carneiro (2001) e Meireles (1999), em cajueiro Anão Precoce. Tais reduções são explicadas por taxas menores de fotossíntese e de metabolismo da planta (Cramer et al., 1989).

\section{Percentagem de pegamento do enxerto}

Na Figura 4 têm-se os dados de percentagem de pegamento do enxerto (PPE), obtidos aos 30 dias após a enxertia (DAE); observou-se efeito estatístico $(p<0,01)$ para o fator salinidade (S), sem entretanto, haver diferença significativa entre clones (C), nem para a interação S x C. Portanto, os clones tiveram comportamento semelhante nos vários níveis de condutividade elétrica da água de irrigação.

A salinidade reduziu de forma acentuada e quadrática (Fig. 4) o pegamento do enxerto, sendo a diminuição, por aumento unitário de CEa (comparados a 0,5 $\mathrm{dS} \mathrm{m}^{-1}$ ), de 21,03, 39,13, $54,28,66,50$ e 75,77\%, respectivamente para tratamentos $\mathrm{S}_{2}$ a $\mathrm{S}_{6}$. $\mathrm{O}$ conteúdo salino das águas, acima de $1,5 \mathrm{dS} \mathrm{m}^{-1}$, diminuiu consideravelmente o percentual de pegamento dos enxertos, aos 30 DAE. Esse fato pode ser atribuído ao aumento da 


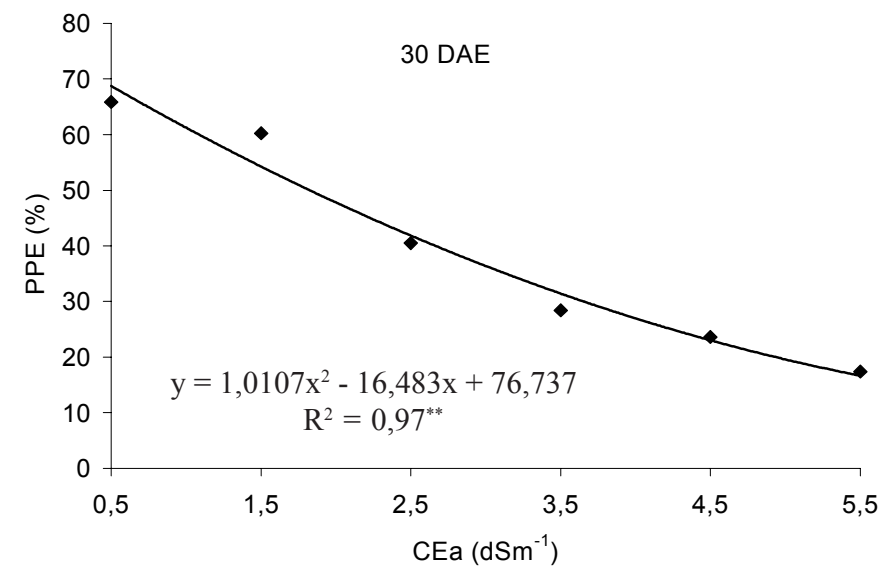

Figura 4. Percentagem de pegamento de enxerto, em função da condutividade elétrica da água de irrigação $(\mathrm{CEa})$, aos 30 dias após a enxertia (DAE) de dois porta-enxertos de cajueiro anão precoce

salinidade no substrato, com o passar do tempo, resultando, conseqüentemente, em menor sucesso no pegamento do enxerto, por diminuir o potencial osmótico da solução do solo, provocando estresse hídrico e, também, problemas de toxicidade e desequilíbrio nutricional das plantas (Fageria, 1989). Meireles (1999), utilizando-se de enxertia por borbulhia, observou efeito semelhante da salinidade da água de irrigação sobre o pegamento do clone de cajueiro Anão Precoce CCP76; quando a condutividade elétrica da água de irrigação aumentou de 0,26 para 2,63 dS m $\mathrm{d}^{-1}$, o índice de pegamento caiu de 79,33 para 1,02\%.

\section{CONCLUSÕES}

1. A salinidade da água de irrigação não afeta a percentagem de germinação, entretanto, prolonga o período germinativo das sementes.

2. A irrigação com água de salinidade superior a $0,5 \mathrm{dS} \mathrm{m}^{-1}$ afeta negativamente a emissão de folhas, o crescimento em altura e o diâmetro do caule das plantas, sendo maior a redução no porta-enxerto CCP1001.

3. Com incremento da $\mathrm{CEa}$, além de $0,5 \mathrm{dS} \mathrm{m} \mathrm{m}^{-1}$, ocorre decréscimo na produção de fitomassa seca total.

4. A percentagem de pegamento do enxerto CCP76 diminui drasticamente com o aumento da salinidade da água de irrigação, em ambos os porta-enxertos, com morte das plantas em níveis de salinidade superiores a $3,5 \mathrm{dS} \mathrm{m}^{-1}$.

\section{LITERATURA CITADA}

Cabarjal, A.C.R.; Sá, F.T. de; Franco, F.G.S. Recomendações para produção, plantio e manutenção de mudas de cajueiro. Fortaleza: EMBRAPA/CNPAT, 1995, 4p. Comunicado Técnico, 08

Carneiro, P.T. Germinação e desenvolvimento inicial de clones de cajueiro anão precoce sob condições de salinidade. Campina Grande: Universidade Federal da Paraíba, 2001. 85p. Dissertação Mestrado

Coelho, M.A. Aspecto da dinâmica da água em solos sódicos e salino-sódicos. Ciência Agronômica, Fortaleza, v.14, n.1-2, p.61-68, 1983.
Cramer, G.R.; Epstein, E.; Läuchi, A. Na-Ca interaction in barley seedlings: Relations to in transport and growth. Plant Cell and Environment, Logan, v.12, p.551-558, 1989.

EMBRAPA - Empresa Brasileira de Pesquisa Agropecuária. Centro de Agroindústria Tropical. Aspectos agroeconômicos sobre a cultura do cajueiro. Fortaleza: 1993. 124p.

EMBRAPA - Empresa Brasileira de Pesquisa Agropecuária. Serviço Nacional de Levantamento e Conservação de Solos. Manual de métodos de análise de solo. Rio de Janeiro, 1997. 212p.

Fageria, N.K. Solos tropicais e aspectos fisiológicos das culturas. Brasília: EMBRAPA/DPU, 1989. 425p. EMBRAPACNPAF. Documento, 18

Fageria, N.K.; Gheyi, H.R. Melhoramento genético das culturas e seleção de cultivares. In: Gheyi, H.R.; Queiroz, J.E.; Medeiros, J.M. (eds). Manejo e controle da salinidade na agricultura. Campina Grande: UFPB-SBEA, 1997. p.363-383.

Ferreira, P.V. Estatística experimental aplicada à agronomia. Maceió: UFAL/EDUFAL/FUNDEPES, 2000, 604p.

FNP, Consultoria \& Comércio. Agrianual 98: anuário estatístico de agricultura brasileira. São Paulo, 1998. 481p. cap.: Caju.

Kramer, D. Cytological aspects of salt tolerance in higher plants. In: Staples, C.; Toenniessen G.H. (eds.) Salinity tolerance in plants: Strategies for crop improvement. New York: John Wiley \& Sons, 1984. p.3-15.

Maas, E.V. Salt tolerance of plants. Applied Agricultural Research, New York, v.1, p.12-36, 1986.

Maas, E.V.; Hoffman, G.J. Crop salt tolerance - current assessment. Journal of Irrigation and Drainage Division; New York, v.103, n.IR2, p.115-134, 1977.

Medeiros, J.F. Qualidade de água de irrigação e evolução da salinidade nas propriedades assistidas pelo 'GAT' nos estados de RN, PB e CE. Campina Grande: UFPB, 1992. 173p. Dissertação Mestrado

Meireles, A.C.M. Salinidade da água de irrigação e desenvolvimento de mudas de cajueiro anão precoce (Anacardium occidentale L.). Fortaleza: UFC, 1999. 60p. Dissertação Mestrado

Menguel, K.; Kirkby, E.A. Principles of plant nutrition. 4 ed. Bern: International Potash Institute 1987. 687p.

Murashige, T.; Skoog, F.A. A revised medium for rapid growth and bioassay with tobacco tissue culture. Physiologia Plantarum, Copenhagen, v.15, n.3, p.437-497, 1962.

Postel, S. Water for agriculture: Facing the limits. Washington: Worldwatch Institute 1989. 54 p. Worldwatch Paper 93

Rhoades, J.D.; Kandiah, A.; Mashali, A. M. The use saline waters for crop production. Rome: FAO, 1992. 133p. FAO. Irrigation and Drainage Paper, 48

Rhoades, J.D.; Loveday, J. Salinity in irrigated agriculture. In: Stewart, D.R.; Nielsen, D.R. (ed.) Irrigation of agricultural crops. Madison: ASA, CSSA, SSSA, 1990. p.1089-1142. Agronomy, 30

Richards, L.A. (ed.). Diagnosis and improvement of saline and alkali soils. Washington: United States Salinity Laboratory, 1954, 160p. USDA. Agriculture Handbook, 60

Silva, J.M.A.; Silva, P.M. Diagnóstico de produção e comercialização de mudas e sementes de espécies frutíferas na região Nordeste do Brasil. Viçosa: UFV; DER; FUNARBE, 1999.215p.

Soares, A.C.D. Tolerância de porta-enxertos e enxerto de cajueiro anão precoce (Anacardium occidentale L.) à salinidade do substrato. Fortaleza: UFC, 1998. 40p. Dissertação Mestrado

Vieira, R.D.; Carvalho, N.M. Teste de vigor em sementes. Jaboticabal: FUNEP/UNESP-FCAVJ, 1994. 164p. 